\title{
LA SOCIOECONOMÍA DEL CAFÉ Y LAS INTERVENCIONES DESARROLLISTAS EN LA REGIÓN OCCIDENTAL DE HONDURAS
}

\author{
Jorge Humberto Orellana Peña*
}

DOI: 10.5377/eya.v10i1.9045

Recibido: 4/02/2019 Aceptado:15/10/2019

\section{RESUMEN}

Entre 2014 y 2018, se realizó un estudio de la economía política del café y el desarrollo humano en los departamentos de Copán, Ocotepeque y Lempira. El objetivo del estudio fue comprender las contribuciones socioeconómicas de la caficultura y su relación con las intervenciones desarrollistas del occidente de Honduras. La investigación contempló una fase cualitativa y una cuantitativa. Se realizaron diversas entrevistas, observaciones, giras de campo y se aplicó un cuestionario a 378 sujetos para traducir percepciones y frecuencias al lenguaje numérico. Se utilizaron software como Atlas. ti y SPSS. Los resultados evidencian una estructura de desigualdad en la repartición de los beneficios de la caficultura. Las familias, con sus modestos ingresos, logran solventar necesidades de alimentación, vivienda, salud y educación, sin embargo, existen diversas formas de empobrecimiento que les condiciona y les coloca en una situación de vulnerabilidad permanente. Cuando los precios del café son buenos, se produce un proceso de reinversión social. Los modelos, programas y estrategias de intervención en nombre de la pobreza y del desarrollo necesitan procesos de deconstrucción cultural y descolonización epistemología que permitan nuevas comprensiones para desnaturalizar la vergonzosa exclusión que vive el occidente de Honduras.

Palabras claves: socioeconomía, caficultura, familias, desarrollo, pobreza, deconstrucción, descolonización, epistemología, intervención, región.

JEL: Q120, O130

\footnotetext{
* Profesor investigador del Centro Regional Universitario de Occidente CUROC, Universidad Nacional Autónoma de Honduras UNAH. email: jorge.orellana@unah.edu.hn
} 


\title{
THE SOCIOECONOMICS OF COFFEE AND THE DEVELOPMENTAL INTERVENTIONS IN THE WESTERN REGION OF HONDURAS
}

Jorge Humberto Orellana Peña

DOI: 10.5377/eya.v10i1.9045

\begin{abstract}
Between 2014 and 2018, a study of the political economy of coffee and human development was carried out in the departments of Copán, Ocotepeque and Lempira. The objective of the study was to understand the socio-economic contributions of coffee growing and its relationship with developmental interventions in western region of Honduras. The research contemplated a qualitative and a quantitative phase. Several interviews, observations, field trips were conducted and a questionnaire was applied to 378 subjects to translate perceptions and frequencies into the numerical language. Software such as Atlas. ti. and SPSS was used. The results show a structure of inequality in the distribution of the benefits of coffee production. Families, with their modest incomes, manage to meet the needs of food, housing, health and education, however, there are various forms of impoverishment that condition them and places families in a situation of permanent vulnerability. When coffee prices are good, there is a process of social reinvestment. Models, programs and intervention strategies in the name of poverty and development need processes of cultural deconstruction and decolonization epistemology that allow new understandings to denaturalize the shameful exclusion that western Honduras is experiencing.
\end{abstract}

KEYWORDS: socioeconomics, coffee growing, families, development, poverty, deconstruction, decolonization, epistemology, intervention, region.

JEL: Q120, O130 


\section{INTRODUCCIÓN}

La caficultura representa una alternativa de vida para miles de familias en Honduras, se cultiva en 15 de los 18 departamentos. El occidente del país aporta el 30\% de la producción nacional. Este artículo presenta una valoración socioeconómica del café y los procesos de intervención del desarrollo en la región occidental. La caficultura aporta ingresos a la economía familiar, pero se desenvuelven entre medio de diversas asimetrías y formas de empobrecimiento. Por medio de esta investigación realizada entre 2014 y 2018 se hace un llamado a la reflexión para acercarse a procesos de deconstrucción cultural y descolonización epistemológica que induzcan nuevas formas de intervenir y comprender la realidad. Los aportes de la caficultura a la macroeconomía nacional, no se han traducido en cambios sustanciales de bienestar humano en las familias productoras. No puede tildárseles de pobres, sino, personas que luchan año con año para solventar diversas necesidades básicas.

Dentro de la actividad cafetalera existe un problema visible de desigualdad. Los mayores beneficios económicos se quedan en los procesos de intermediación y exportación. El café, sigue siendo una actividad productiva extractivista, desperdiciando el potencial que existe en el consumo local $y$ en la comercialización de cafés diferenciados de alta calidad. En el pensamiento desarrollista existe una racionalidad económica con visiones de una realidad mercadológica, de competencia y productividad; un pensamiento dicotómico que condiciona las formas de comprender los procesos de intervención. El estudio fue realizado en los departamentos de Copán, Ocotepeque y Lempira. Recopila decenas de observaciones y recomendaciones de familias, técnicos, directivos y demás gestores del desarrollo.

Por tanto, las valoraciones vertidas en este estudio conducen a la reflexión de pensamientos alternativos que desnaturalicen la vergonzosa exclusión social que sufre el occidente de Honduras. Debe volverse la mirada hacia las potencialidades de la región, deben buscarse alternativas para un modelo de economía política del café y desarrollo humano que privilegie lo local, con enfoque en las personas y por encima de toda racionalidad económica; debemos acercarnos a nuevos paradigmas de intervención; a verdaderos espacios de justicia cognitiva; se deben fomentar pensamientos críticos hacia un modelo de desarrollo que ha dejado miseria, exclusión, exilio y expolio de la riqueza humana; es una invitación para revisar las formas de intervención y fomentar una cultura institucionalizada para la socioeconomía del café en el occidente de Honduras. 


\section{MARCO TEÓRICO O}

\section{REFERENCIAL}

La caficultura en Honduras se produce en 15 de sus 18 departamentos, el país ocupa el primer lugar de producción y exportación en Centroamérica, el tercero en Latinoamérica y el quinto exportador de café en el mundo. El café se extendió desde Etiopía y Abisinia hacia Holanda y Francia (Orellana y Carranza, 2013a). En América fue introducido entre los años de 1714 y 1728 (Montes, 1928). El café llegó a gran escala a las colonias de Surinam, Martinica, Santo Thomas, la española en República Dominicana, Haití y Cuba (Alvarado, 1936). En 1799 llegó a Honduras a través del Puerto de Trujillo. El café llegó a la región occidental del país entre los años de 1835 y 1850. Provino de Guatemala y El Salvador dada la propagación que existía en esos países (Carranza, 2012).

La reforma liberal de Marco Aurelio Soto y Ramón Rosa a partir de 1876 serían los detonantes para la llegada progresiva de las estrategias desarrollistas; a partir de allí, se instalaron los enclaves económicos extractivistas y se abrieron las puertas para el capital extranjero. La caficultura siempre estuvo en la mente de los ideólogos reformistas; leyes, decretos y otras disposiciones motivaban su expansión y producción en su afán de insertarse en el mercado internacional. La caficultura tomó un giro diferente del enclave minero $y$ bananero, las políticas públicas y los incentivos no resultaron significativos para su expansión. Fue hasta la década del setenta del siglo XX en la cual la caficultura comenzó su verdadera expansión concentrada mayormente en pequeños productores.

Con la reestructuración del sistema económico a partir de la Segunda Guerra Mundial, se implementaron diversas teorías de desarrollo para motivar la actividad económica en países latinoamericanos. La ideología del desarrollo reemplazó la figura del progreso, iniciada siglos antes con los griegos y romanos (Orellana, 2018). La reconfiguración del pensamiento dicotómico entre desarrollados y subdesarrollados condicionó la forma de comprender la realidad para intervenir y transformar. Los procesos de intervención desarrollistas han influido para que prevalezca una visión mercadológica del mundo (De Souza, et. al., 2005, p. 71). El discurso ha sido la construcción de una racionalidad económica que privilegia el mercado, la competencia, el consumo, el capital y la acumulación de la riqueza. "Bajo esta visión, todo se vende, desde los principios hasta la naturaleza" (Ibíd., p. 71). De tal manera que, el proyecto económico y cultural del desarrollo (Escobar, 2010) galvanizó el pensamiento y ahora 
condiciona la realidad de la caficultura nacional.

\subsection{Aproximaciones teóricas a la socioeconomía del café}

La economía del café representa una alternativa para alrededor de 30,000 familias en el occidente de Honduras. juntos aportan el $30 \%$ de la producción nacional. La caficultura se mezcla entre acciones de economía política y acciones de política económica, su diferenciación es crucial para comprender la realidad de uno de los sectores que contribuye significativamente con divisas al país. La política económica está a cargo del Consejo Nacional del Café (Conacafé); es el responsable, según Decreto Legislativo 2972002, de elaborar políticas y estrategias de corto y mediano plazo para regular y coordinar la actividad cafetalera en el país. Como parte de la política económica, su objetivo es buscar una mayor competitividad del rubro para la estabilidad y crecimiento de la economía nacional. Por su parte, la economía política se define como la ciencia que trata de las relaciones sociales de producción. Su propósito es estudiar las leyes económicas que están inmersas en la producción, en la distribución, el cambio y el consumo de bienes materiales en una sociedad (García, 2000). Para Engels (1878), la economía política "es la ciencia de las leyes que rigen la producción y el intercambio de los medios materiales de vida" (p. 140).

La caficultura se entremezcla entre una serie de acciones dictadas por la institucionalidad cafetalera, el Gobierno y decretos emitidos por el Congreso Nacional. De la misma forma, están en constante interacción los factores de producción y todo su entramado de relaciones, prácticas y significados. Las relaciones productivas dentro de las familias cafetaleras cambian en la medida de las circunstancias. La economía política se convierte en una ciencia dinámica y viva, puesto que la realidad de los productores de café cambia, se modifica y se transforma año con año. Dentro de los análisis económicos se ha podido validar el aporte significativo del café a la socioeconomía regional. Sin embargo, al existir cierto abandono de variables sociales en las comunidades, es notorio que las familias productoras se convierten en subsidiarias del Estado para atender sus problemas de salud, alimentación, vivienda y acceso a la educación. Sumado a esto se encuentra el problema de intermediación y concentración de la riqueza en ciertos eslabones de la cadena de valor del café.

\subsection{El contexto socioeconómico del occidente de Honduras \\ El occidente de Honduras está ubicado al noreste de la República de Guatemala y El Salvador y al oeste de los departamentos de}


Santa Bárbara y Cortés, con una superficie de 9,100 km2 que representa el 8\% del territorio nacional (PNUD, 2009, pp. 417-435). La topografía es muy irregular por ubicarse en la zona de la cordillera central y del sur, de la cual se desprenden las sierras del Gallinero, Merendón, Celaque y Puca Opalaca, cuyas altitudes máximas oscilan entre $1400 \mathrm{~m} / \mathrm{nm}$ y $2385 \mathrm{~m} / \mathrm{nm}$ (Orellana y Carranza, 2013b). Geológicamente es la región más antigua y agreste, con apenas $25 \%$ de territorio relativamente plano (Carranza, 2012). El occidente de Honduras comprende, principalmente, los departamentos de Copán con 382,722 personas, Lempira con 351, 652 y Ocotepeque con 151,516 personas (INE, 2019).

La socioeconomía de la región ha estado marcada por la historia de su tiempo. Los Nahuas fueron el grupo indígena que tuvo mayor influencia en la cultura y en el comercio en el occidente del país; el añil y el tabaco fueron rubros de relevancia en tiempos de la Colonia. Sobresalen otros productos como café, granos básicos, verduras, legumbres, frutas, caña de azúcar, ganado, explotación de madera, minería y venta de servicios. Actualmente la economía de la región depende principalmente de la caficultura, de las remesas familiares recibidas por emigrantes y la pequeña empresa de carácter familiar. La producción agrícola del occidente es básicamente de subsistencia y la misma se desenvuelve en un sinnúmero de dificultades de carácter estructural y abandono progresivo.

El dinamismo económico se encuentra debidamente diferenciado en cada uno de los departamentos, por ejemplo, en Copán sobresalen municipios como Santa Rosa, Copán Ruinas, Corquín, Cucuyagua y Florida; En Ocotepeque, el auge económico radica en los municipios de Ocotepeque, La Labor y San Marcos. En Lempira, sobresale Gracias y Lepaera. Sin embargo, una cantidad significativa de municipios, aldeas y caseríos enfrentan problemas de pobreza humana que obliga a sus habitantes a emigrar hacia las zonas urbanas y hacia países como España y Estados Unidos (Flores, 2017). Los datos del Programa de las Naciones Unidas para el Desarrollo (PNUD) de 2012, muestran leves mejorías en educación en algunos departamentos como Lempira, sin embargo, Dolores Merendón en Ocotepeque y San Agustín en Copán son municipios con menores índices de desarrollo humano (PNUD, 2012).

La inversión del Estado en el occidente está condicionada por la prioridad que tiene la zona norte, centro y sur de Honduras. Las principales recaudaciones fiscales se producen en esas zonas, así como la mayor parte de los proyectos de infraestructura. Entre 2010 - 2016 el peso de las contribuciones tributarias de Copán, Ocotepeque y Lempira, todos juntos, fue de 
3.39\% del aporte nacional; el aporte de Cortés fue 24.78\% y Francisco Morazán 67.99\% (Fosdeh, 2017). En la última década, las prioridades del país ha sido el fortalecimiento del sector financiero, comunicaciones, comercio textil y construcción. Estas son economías de enclave que no están encadenadas con otras actividades productivas. "Paradójicamente, Agricultura, Ganadería, Silvicultura y Pesca es el sector que recibe la menor colocación de recursos monetarios" (Fosdeh, 2017, p. 14). Estos sectores absorben el $26.7 \%$ del empleo en Honduras. Ante los escenarios de mayor endeudamiento público, la prioridad del presupuesto para seguridad y defensa, la disminución presupuestaria para salud, educación y los bajos porcentajes de crecimiento económico, es notorio que, pensar en mejorar sustancialmente las condiciones de vida de la población del occidente de Honduras, representa un desafío de grandes proporciones para cualquier estrategia de intervención.

\section{METODOLOGÍA Y FUENTE DE}

\section{DATOS}

Durante 2014 - 2018 se realizó esta investigación con diseño metodológico mixto que vinculó la economía del café y el desarrollo humano en la región occidental de Honduras. En su alcance descriptivo se indagaron percepciones desde las familias productoras y gestores del desarrollo. Para la fase cualitativa se usaron herramientas como entrevistas, observación participante $y$ grupos focales. En su diseño cuantitativo se utilizó un cuestionario del cual se extrajeron tablas, gráficos y frecuencias en función de la información recopilada. Los sujetos participantes fueron familias productoras de café, gestores del desarrollo y demás actores dentro de la cadena de valor de la caficultura regional. La muestra fue seleccionada en función de los datos del Ihcafé (2016). Del universo de productores de café se consideró una población de 24,716 , con un margen de error del 5\% y nivel de confianza del 95\%. La muestra de 378 sujetos se distribuyó de forma proporcional de acuerdo con el número de productores registrados en Copán, Ocotepeque y Lempira.

El entorno territorial del estudio fue Copán, Ocotepeque y Lempira. Se escogieron cinco municipios por cada departamento en los cuales se produce la mayor cantidad de café (Ihcafé, 2016). Estos municipios son representativos de la producción de café regional, por lo cual, tanto el cuestionario como las entrevistas fueron aplicadas en: Corquín, Florida, Santa Rita, San Pedro y Cucuyagua, Copán. En Lempira: La Iguala, Lepaera, La Unión, Gracias y San Rafael. En Ocotepeque: San Marcos, Sensenti, La Labor, San Francisco del Valle y Mercedes. 
Figura 1: mapa territorial de los municipios de estudio en el occidente de Honduras

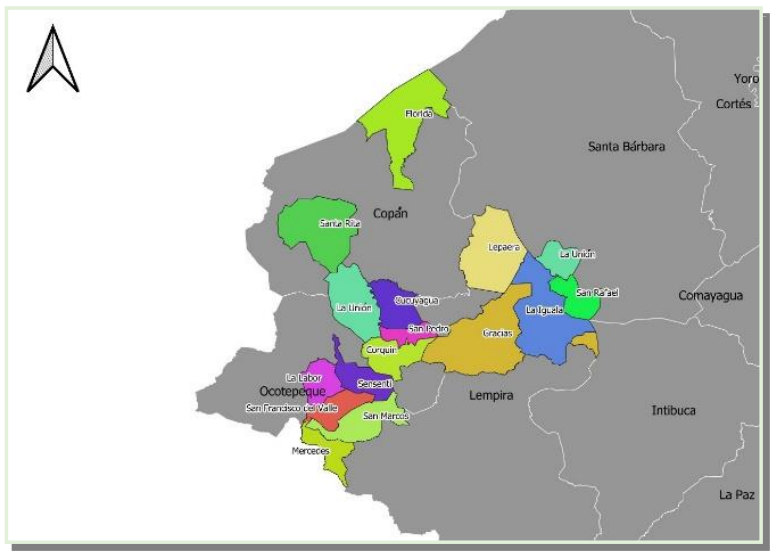

Fuente: Elaboración de Rigoberto Martell

Los grupos focales fueron realizados en Santa Rosa de Copán, Lepaera Lempira y San Marcos Ocotepeque. En su etapa cualitativa se describieron los aportes económicos y sociales de la economía del café y se analizaron las formas de intervención del desarrollo en la región. Para el análisis del estudio, las percepciones derivadas de entrevistas y cuestionarios fueron traducidas a frecuencias para extraer datos numéricos (Sampieri et. al., 2006, 2014), esto permitió, por medio del software SPSS, extraer tablas, porcentajes y gráficos. Para la fase cualitativa se utilizó el software Atlas. ti. El análisis fue ordenado utilizando familias de categorías y en cada familia se utilizaron subcategorías, las cuales fueron codificadas de acuerdo con 30 entrevistas realizadas. La combinación de herramientas cualitativas y cuantitativas se hizo con el propósito de realizar una mejor triangulación y validación de los resultados del estudio.

\section{RESULTADOS Y DISCUSIÓN}

La caficultura en Honduras se ha caracterizado por estar contenida en una pirámide de desigualdad evidente, en la cual, la base está representada por miles de familias que viven del rubro al hacer sus mayores esfuerzos para la productividad del país, sin embargo, en los siguientes eslabones, se concentra la mayor parte de la riqueza de tal actividad (Orellana, 2018). En la cosecha 2017 - 2018 se exportaron 9.3 millones de sacos de 46kg., lo cual representó el ingreso de al menos 1,300 millones de dólares. Los países importadores fueron Alemania, Bélgica, Estados Unidos, Francia, Italia y Corea. A pesar de los beneficios económicos que produce la caficultura, esta presenta marcadas asimetrías en sus procesos de acopio, intermediación y comercialización, sin embargo, alrededor del café se mueven otros negocios que dinamizan la economía regional.

4.1 El bienestar económico de las familias productoras de café

La economía familiar, en alguna medida, depende de la actividad cafetalera, sus ingresos año con año, solventan una serie de necesidades. Cuando los precios internacionales son favorables, la actividad se convierte en un proceso de reinversión y ampliación. Desde la percepción de las familias productoras, el café ayuda, pero no lo es todo, porque los beneficios económicos se 
quedan, principalmente, en los compradores intermediarios $y$ en los beneficios exportadores. En promedio cada productor tiene entre 3 y 5 manzanas de café, lo cual significa que este rubro debe analizarse desde una visión complementaria y no absoluta. De la misma forma, avanzar en los eslabones de la cadena y en procesos de certificación, puede convertirse en una alternativa para mejorar la economía familiar. La información recopilada con las familias productoras indica que dentro de la cadena de valor los mayores beneficios se quedan en los exportadores y en los compradores intermediarios. Otro de los que se benefician con la actividad cafetalera es el Estado con el pago que recibe por impuestos y por las mismas divisas.

Figura 2: Para usted, ¿quién se beneficia más con la cadena productiva del café en el occidente de Honduras?

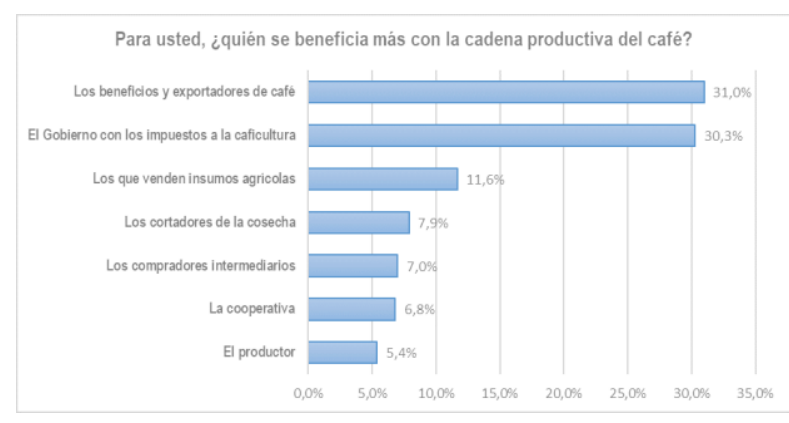

Fuente: Propia, con datos de cuestionario UNAH - 2018

Dentro de los eslabones de la cadena de valor del café se conformó tempranamente una estructura intermediadora que ha condicionado los precios pagados al productor. Estas estructuras han sustituido sistemáticamente las funciones del sistema bancario al convertirse en prestadores de última instancia con el respaldo de la respectiva cosecha. El productor, de esta forma, queda condicionado a las normativas del comprador intermediario. Desde la percepción de las familias productoras, el precio pagado por su esfuerzo no se corresponde con la calidad de café que entregan, de la misma forma, no existen supervisiones para las pesas y medidas con las que cuentan decenas de compradores de café en la región, tampoco existen penalizaciones para quienes descuidan la calidad del grano, por lo que, es común que los intermediarios revuelvan variedades y diversas calidades del aromático.

Estos factores son debidamente conocidos por la institucionalidad cafetalera, por lo que las familias productoras sienten que no se están atendiendo sus problemas, lejos de eso, las instituciones viven de las aportaciones de miles de productores. Para el productor "los de no dejan desarrollarse a los pequeños, a usted, prácticamente, casi lo obligan a que tiene que vender el café de tal manera, porque solo ellos pueden procesarlo, lo monopolizan, hay casi un monopolio en la intermediación y comercialización" (Entrevistas, Corquín, Copán, 2017). A pesar de las dificultades, las familias productoras consideran que la caficultura les ha permitido 
un crecimiento económico muy moderado; $70.6 \%$ de la muestra consideran haber mejorado su economía, $23.8 \%$ manifestaron que muy poco y $5.6 \%$ adujeron que no han tenido ningún beneficio económico. En años buenos, la familia amplía sus horizontes, mejora su vivienda y adquiere algún tipo de maquinaria y añade una parcela más.

En años malos, los problemas de la caficultura se perciben de forma distinta, las plagas y las enfermedades se vuelven más difíciles de resolver. Los ingresos recibidos del café se diluyen entre los altos costos de los insumos, los impuestos que el Gobierno impone, el alto costo de los créditos recibidos, la construcción de patios, despulpadora $y$, cuando se desea avanzar en la cadena de valor, afloran las necesidades de electricidad, tostadora, molinos y otros materiales necesarios para la comercialización del café. Este estudio ha evidenciado la necesidad de realizar esfuerzos mayores de coordinación institucional. La caficultura no puede reducirse únicamente a una visión extractivista de crecimiento económico permanente; debe abrirse un campo de discusión para encaminar los esfuerzos hacia una cultura de consumo local, una racionalidad económica que contemple “intercambio de servicios entre miembros de la comunidad con base en sistemas alternativos de medición del valor del trabajo" (Santos, 2012, p. 67).
Esos esfuerzos necesitan, obligadamente, pensamientos alternativos hacia la idea de desarrollo. La coordinación institucional es fundamental para avanzar en los eslabones de la cadena de valor y establecer una industria alrededor del café que contemple la institucionalización de la cultura cafetalera en la región. Para tales propósitos, es necesario la creación de una escuela de pensamiento alternativo en la cual se debatan los procesos de intervención desarrollista en la región. Esto permitirá la comprensión de la realidad desde una mirada más incluyente que conduzca hacia verdaderos procesos de bienestar humano. de la misma forma, es necesario la instalación de un observatorio de la caficultura que contemple una plataforma virtual para visibilizar la familia productora de café y la posibilidad de comercialización directa hacia el mercado internacional.

Este estudio muestra la necesidad de continuar con el fortalecimiento de instancias organizativas que han sido creadas en la última década. Las empresas asociativas, las iniciativas emprendedoras para procesar café, la creación de cooperativas cafetaleras, son procesos que posibilitan una mejor circulación de dinero o localización monetaria (Max - Neef, 2010). Para ello, es necesario crear mesas sectoriales para atender las necesidades de la caficultura regional y el fortalecimiento institucional, pues cualquier estrategia de beneficio comunitario necesitará de instituciones que 
proporcionen la infraestructura que sirva al humano para crear orden y reducir la incertidumbre (North, 1981, 1990). Sin embargo, toda iniciativa debe emprenderse bajo visiones contextuales y no solamente bajo visiones mercadológicas de la realidad.

Por tal razón, este estudio ha enfatizado en la imperiosa necesidad de abordar procesos de deconstrucción cultural y descolonización epistemológica que provoquen cambios significativos en las personas y comunidades. La deconstrucción es un proceso para desplazar y visibilizar; es una dinámica de negación y contradicción que le permite afirmar, pero, a su vez, toma partido en la medida que va construyendo en el proceso (Ayala, 2013). Esto supone la creación de nuevas concepciones de racionalidad, de tiempos y saberes (Chavarría y García, 2004). Por tanto, deconstruir la idea de desarrollo implica comprender que culturalmente somos rehenes de premisas que nos alejan del otro, del sentido comunitario, de representar las intervenciones como objetos; deconstruir representa el desmantelamiento de dicotomías como desarrollado y subdesarrollado; moderno y tradicional; avanzado y atrasado. Deconstruir significa la comprensión de que el conocimiento también se basa en desconocimientos (Santos, 2010b).

Por su parte, la descolonización epistemológica alude a la necesidad de comprender que los modelos, las recetas y toda estrategia de intervención no es inocente en sí misma; responde a un origen histórico y a una intención política e ideológica, el cual por medio de premisas se establece un discurso que condiciona la forma de intervenir en la realidad. La descolonización significa romper con la imposición colonial que aún existe en el saber, en la cultura y en la comprensión del mundo, porque el colonialismo con todas sus dicotomías "continuó reproduciéndose de modo endógeno" (Santos, 2010a, p. 8). Bajo esa idea, se ha creído que existen razas superiores e inferiores; que el único conocimiento válido es el científico, descartando los demás saberes; que los países deben aceptar los modelos que fueron concebidos en otros contextos con la premisa que unos deben generar, otros transferir y muchos adoptar. Esto se convirtió en una racionalidad instrumental universalizada con la idea de que no era necesario comprender los contextos, bastaba seguir recetas y modelos para transformar la realidad con la meta única de ser desarrollado.

Todo ello, ha conducido a una opresión y a un epistemicidio (Santos, 2010b; Freire, 1970), con lo cual se han dejado de lado los análisis de una realidad multidimensional, que no puede ser homogénea ni universal, por lo cual, la descolonización epistemológica sugiere, tanto a la ciencia como a la sociedad, 
abrir su campo de visión hacia otros saberes, a conocimientos y mundos de otro modo (Escobar, 2003); a la creación de diferencias iguales y relaciones horizontales, a la crítica en el sentido de Michel Foucault (1995); al cuestionamiento de modelos que no han funcionado y han causado mayor miseria en el mundo y, especialmente, a la construcción de caminos propios. Por consiguiente, la caficultura está sumergida dentro de esas racionalidades que no permiten a la familia productora representarla como propia.

Tabla 1. Beneficios de la caficultura para las familias productoras del occidente de Honduras

\begin{tabular}{|l|l|c|}
\hline \multicolumn{2}{|c|}{ La caficultura ha ayudado a: } & Porcentaje \\
\hline & Mejorar mis ingresos familiares & $38,2 \%$ \\
\hline $\begin{array}{l}\text { Mejorar la educación de mis hijos } \\
\text { Mejorar la salud y alimentación } \\
\text { en el hogar }\end{array}$ & $20,4 \%$ \\
\hline \begin{tabular}{l|l} 
Mejorar el medio ambiente \\
Me ha ayudado a organizarme
\end{tabular} & $10,0 \%$ \\
\hline No me ha ayudado mucho & $4,4 \%$ \\
\hline \multicolumn{2}{|c|}{ Total } & $\mathbf{1 0 0 , 0 \%}$ \\
\hline
\end{tabular}

Fuente: Propia, con datos de cuestionario UNAH - 2018

Con los modestos ingresos que se reciben, la familia solventa necesidades que corresponden al mismo Estado. La muestra aplicada reveló que con la caficultura la familia mejora sus ingresos $(38.2 \%$ de los consultados); mejora la educación de sus hijos (20.4\%); ayuda a mejorar la salud y alimentación en el hogar (20.7\%), entre otros aspectos sociales como la organización y cuidado del ambiente.

4.2 Las contribuciones sociales de la caficultura para las familias productoras

Las observaciones realizadas en este estudio han evidenciado que miles de productores se dedican a una sola actividad (Orellana, 2018). Quienes gozan de mayor bienestar social son aquellos que han logrado diversificar sus actividades productivas. Los procesos de reinversión se convierten en una obligación de corto plazo para asegurar mayores ingresos que solventen diversas necesidades. Sin embargo, esto es complejo, puesto que existen otras circunstancias que condicionan las actividades agrícolas; la tenencia de la tierra, los espacios disponibles, la seguridad ciudadana, las distancias del hogar a la finca, el difícil acceso al crédito, la escasa asistencia técnica, el alto costo de los insumos, se convierten en factores condicionantes de las labores en el campo. En las entrevistas, las opiniones son diversas pero coincidentes, "cuando hay café todos comen rico"; "yo gradué a mis hijos"; "gracias a Dios, nosotros hemos estudiado gracias a la caficultura"; "yo creo que, en el caso mío, en el hogar diría que las necesidades las tenemos satisfechas" (Entrevistas, 2016 - 2017).

Lograr estados mayores de bienestar social es contar con acceso a la salud y a la educación, a una mejor alimentación y acceso a una 
vivienda digna. Si bien es cierto la caficultura aporta al llamado desarrollo humano de la región, no es menos cierto que, existen formas de empobrecimiento que, poco a poco, expolian la riqueza humana. Por tal razón, a una familia productora de café no puede llamársele pobre (Jansen, 1993), este ha sido parte del discurso desarrollista institucionalizado para representar a las personas como objetos pasivos y siempre necesitados de ayuda y no como sujetos activos constructores de su propia realidad.
Sin embargo, las formas de empobrecimiento de un modelo de desarrollo económico que se impulsa por diferentes medios lesionan cada vez más la economía familiar, a tal grado que se van deshaciendo de sus bienes para honrar compromisos de pago y miembros de la familia se ven en la obligación de emigrar fuera del país para solventar necesidades básicas dentro del hogar.

Figura 3: Bienestar en vivienda, salud y educación de las familias productoras de café
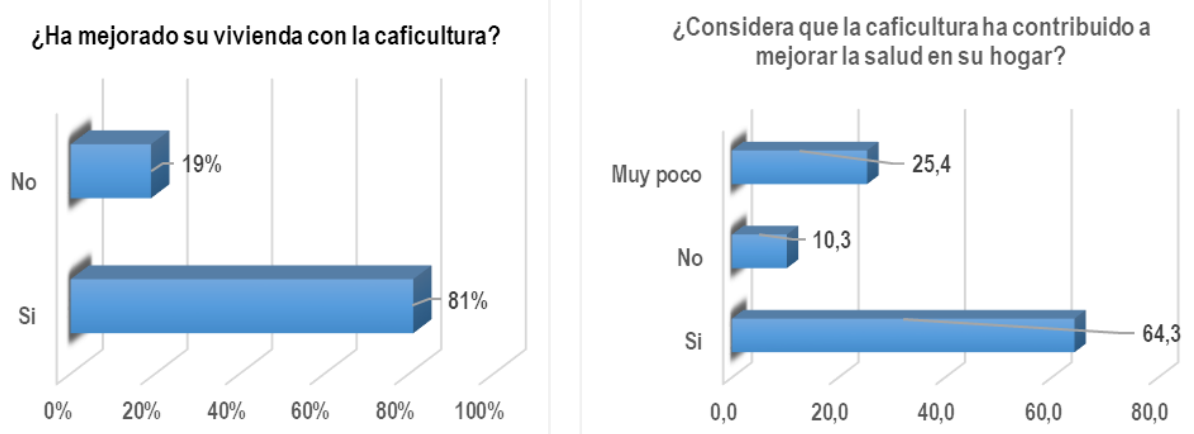

¿Considera usted que la caficultura ha mejorado la educación en su comunidad?

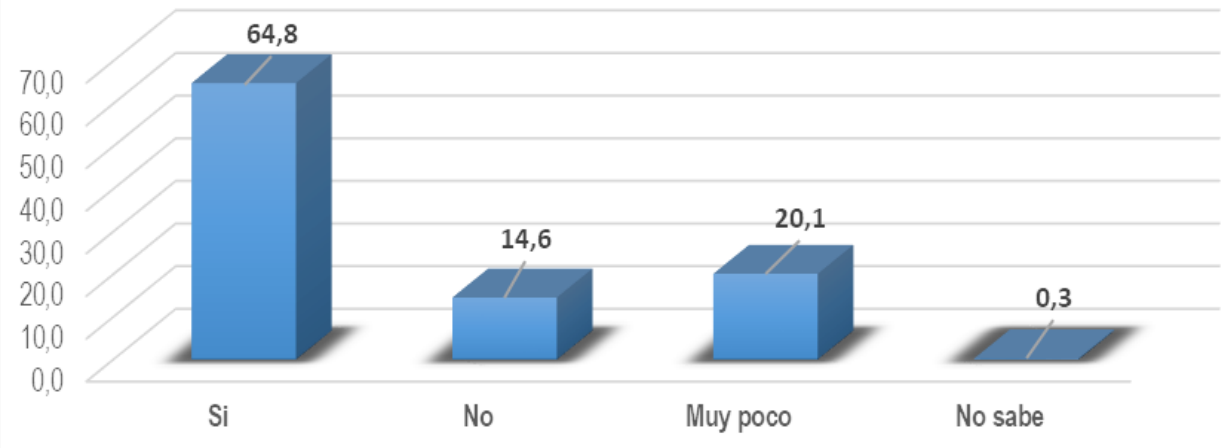

Fuente: Propia, con datos de cuestionario UNAH - 2018

Las familias productoras consideran $(81 \%$ de los consultados), que han mejorado sus viviendas. $64.3 \%$ consideran que han mejorado su salud y 64.8 consideran que han 
mejorado la educación en las comunidades por medio de la caficultura. Si de los ingresos que produce el café la familia tiene que pagar el alto costo de medicamentos que no están disponibles en los centros de salud y hospitales, los altos costos de materiales de construcción, la incontrolable alza de los precios de los alimentos, el alza cada vez de la energía eléctrica y demás servicios públicos, los costos que implica mandar a varios hijos a la escuela, colegio o universidades, es indudable que, poco a poco, el bienestar familiar se ve lesionado. Este subsidio que la familia otorga al mismo Gobierno cuando el Estado no atiende todas estas necesidades, conducen a formas de empobrecimiento que colocan a una región en una situación de vulnerabilidad permanente. ¿Cómo podría un productor avanzar en los eslabones de la cadena de valor del café, si no cuenta con el apoyo para tal propósito? Si el productor, para mejorar su bienestar socioeconómico, quiere procesar y comercializar el café, se enfrentará con la burocracia administrativa, con los altos costos de la maquinaria y equipo; se enfrentará con un cuasi monopolio en el proceso de comercialización y exportación. Se enfrentará con una compleja red de organizaciones e instituciones con estrategias, visiones y agendas propias, sin verdaderos procesos de coordinación en sus intervenciones regionales.
Sin duda, la pobreza es una condición inhumana, humilla, lastima, degrada y lleva a las personas a la desesperación (Rahnema, 1996). En Honduras, de los 8.8 millones de personas, 6.1 millones viven en condiciones de pobreza; es decir, el 68.8\% de la población, de los cuales, $24.7 \%$ son pobres relativos y 44.2\% son pobres extremos (Fosdeh, 2017). Entre 2001 y 2016 se han gastado 421 mil millones de lempiras en nombre de la pobreza (Ibíd.). Sin embargo, deberá, necesariamente, hacerse un esfuerzo de nuevas interpretaciones para el análisis de la pobreza, la miseria y bienestar social. Deberá debatirse desde la Academia y otros sectores acerca de un modelo de desarrollo que condena a las personas al exilio, pues, muchas veces, "la miseria humana no es la falta de dinero, sino la falta de conocimiento de quienes somos" (Falck, 2000, p. 2). ¿Qué modelo de desarrollo que garantice el bienestar social de la población es posible cuando estos modelos han fracasado en el mundo?, ¿Qué tipo de racionalidad económica sería necesaria para colocar a la persona por encima de las pretensiones de un mercado expansionista?, ¿Qué tipo de caficultura puede garantizar sostenibilidad de todas las formas de vida dentro de las próximas décadas?, ¿Podemos tener discusiones entre alternativas de desarrollo y alternativas al desarrollo?, ¿Podría hablarse de ser feliz en vez de ser desarrollado? 
La mayoría de las intervenciones tienden a vincular sus objetivos con la búsqueda de mejores condiciones de vida para la población, sin embargo, esas estrategias contienen premisas que ahora se encuentran en crisis. Si la meta es ser desarrollado no hay mucho que hacer, basta seguir los mismos modelos o paradigmas dentro de una teleología desarrollista. Esas premisas han conducido a que las personas imiten una imagen caracterizada por la opulencia, la acumulación y el desperdicio; invitan al consumismo de alimentos globalizados con probables daños al organismo, inducen a asumir un sistema educativo caracterizado únicamente por la transferencia de información; repetitivo, imitador y poco creativo. Invita al crecimiento infinito, no importando si con ello se lleva de encuentro a la Naturaleza. Ese tipo de modelo de desarrollo con toda su carga semántica es la que ha prevalecido en cada territorio hondureño, ha contado con el apoyo de toda la institucionalidad y su discurso se transmite como verdad absoluta. Ese tipo de desarrollo impositivo, que no toma en cuenta los contextos, los sueños, realidades, esperanzas $\mathrm{y}$ aspiraciones de comunidades particulares, es el que permanece latente como un orden natural de la existencia, han sido modelos que incumplieron sus promesas, puesto que nunca la población estuvo tan desigual y el planeta tan contaminado, condenando con ello a miles de personas a la miseria y a diversas formas de exclusión.

En Honduras, los modelos económicos y sociales inmersos en la caficultura y en otras actividades productivas han sido la reproducción de aquellos considerados universales; esos modelos, "no son malos porque son universales, sino porque localmente son irrelevantes, ya que no llegan como una opción de referencia, sino como los únicos posibles" (De Souza, et. al. 2005, p. 313). Esas visiones únicas de la realidad imposibilitan mirar los ausentes contenidos en los presentes y, por tal razón, es más fácil copiar, reproducir y ejecutar. Otras alternativas implicarían un esfuerzo mayor de pensamiento. Por ejemplo, algunas actividades económicas del occidente de Honduras pueden encadenarse con otras para generar un mayor dinamismo socioeconómico. Una cooperativa cafetalera puede vincular su quehacer con un sitio recreativo, pueden pensar en una empresa adicional para dar valor agregado a las frutas que se producen dentro de la finca, de esta manera, la familia productora no solo recibiría ingresos por el café, sino, por las naranjas, aguacates, paternas, hortalizas y pacayas que en su finca se producen. El productor sabría que hay una empresa que comprará sus productos para darles valor agregado, esto significaría mayores fuentes de empleo, mejoras sustanciales en salud, 
alimentación, educación y otras necesidades básicas. Todo esto sería posible con la creación de centros de acopio que pueden ser impulsados por gobiernos locales, organizaciones no gubernamentales y otras instituciones de relevancia regional. Si las

\section{CONSIDERACIONES FINALES}

La socioeconomía del café en la región occidental de Honduras necesita de nuevos paradigmas en sus procesos de gestión e intervención. El desarrollo que hemos conocido ha perdido su esplendor $y$ ha dejado vacíos, rupturas y fracasos desde hace décadas. Su afán ha estado centrado en promover el crecimiento económico de una región o país, sin embargo, ese crecimiento económico no se ha traducido en verdaderos cambios en el bienestar social de las personas. La caficultura sigue siendo una actividad productiva extractivista, su afán es competir ante un mercado internacional y generar divisas al país, las cuales se quedan en grupos reducidos de la población. La dinamización de la economía regional debe volver la actividad cafetalera en una verdadera cultura; una cultura que contemple el consumo interno, el acercamiento de los productores a los últimos eslabones de la cadena de valor y en propiciar condiciones para crear industrias alrededor del café. $\mathrm{El}$ encadenamiento con otras actividades es crucial y el aprovechamiento de la comunidades se involucran en sus propias aspiraciones podría representar modos de vida social de mayor relevancia socioeconómica y con verdadera coherencia con su entorno.

diversificación productiva que puedan conducir a la creación de empresas locales, generadoras de mayores beneficios sociales para las comunidades.

Es evidente que las familias productoras de café gozan de un mejor bienestar que el resto de la población. Sin embargo, año con año, al incrementarse sus cargas impositivas y otros servicios públicos, van lesionando su economía familiar. Los productores subsidian socialmente al mismo Estado. Por lo cual, cada Gobierno con sus diversas medidas y políticas públicas se convierte en causa fundamental de diversas formas de empobrecimiento. El bienestar social de las familias productoras puede mejorar si se realizan esfuerzos de deconstrucción cultural y descolonización epistemológica que permitan mirar la realidad con otros ojos. Una realidad que imita, repite y con cada fracaso, vuelve a cometer los mismos errores; duplica esfuerzos, es impositiva y no es incluyente. Necesitamos formas diferentes de actuar para ser nosotros mismos; pensar como nosotros para ser nosotros. Se requiere construir nuestra propia realidad para no asumir la de otros. Se necesitan ideas que inspiren, economías solidarias que 
privilegien lo local, se demanda del compromiso de todos para crear proyectos, programas y comunidades que construyan felicidad para todas las formas de vida, incluyendo la indivisibilidad con el Planeta.

\section{BIBLIOGRAFÍA}

Ayala Aragon, O. (2013). Humanidades y ciencias sociales: Comunicaciones. La deconstrucción como movimiento de transformación. Ciencia, Docencia y Tecnología, (47), pp. S/D. Recuperado de: http://www.scielo.org.ar/scielo.php?script=s ci_arttext\&pid=S1851-17162013000200003

Alvarado, J. A. (1936). Tratado de Caficultura Práctica. Guatemala: Tipografía Nacional.

Carranza, A. (2012). Historia y Cultura del Café en el Occidente de Honduras. Aromas, Montañas y Gente. Tegucigalpa, Honduras: PROMECAFE/IHCAFE/BID/FOMIN. Impresiones Industriales.

Chavarría, M., y García, F. (2004). Otra globalización es posible. Dialogo con Boaventura de Sousa Santos. ICONOS, (19), pp. 100-111.

De Souza Silva, J., Cheaz, J., Santamaría, J., Mato, M., Lima, S., Castro, A., Salazar, L., Maestrey, A., Rodríguez, N., Sambonino, P., y Álvarez- González, F. (2005). La Innovación de la Innovación Institucional: De lo universal, mecánico y neutral a lo contextual, interactivo y ético. Quito, Ecuador: Artes Gráficas SILVA.
Escobar, A. (2010). Una minga para el postdesarrollo: lugar, medio ambiente $\mathrm{y}$ movimientos sociales en las transformaciones globales. Perú: Programa Democracia y Transformación Global, Universidad Nacional Mayor de San Marcos. Facultad de Ciencias Sociales.

Escobar, A. (2003). Mundos y Conocimientos de otro Modo. El programa de investigación de modernidad/colonialidad latinoamericano. Tabula Rasa, (1), 51-86.

Engels, F. (1878). La Revolución de la Ciencia de Eugenio Dühring. Moscú: Instituto del Marxismo-Leninismo \& Editorial Progreso, Moscú.

Flores, M. (2017). Territorios de la Migración Internacional de Honduras. Tegucigalpa, Honduras: CEAT/UNAH.

Fosdeh (2017). Ejercicios iniciales en cálculo de pobreza multidimensional. Recuperado de 2018

de:http://www.fosdeh.com/2017/10/hondura s-persona-pobre-multidimensionalmuestra-alrededor-siete-indicadorescarencia/\#prettyPhoto

Fosdeh (2017). Inversión pública. La ruta del desarrollo sostenible. Tegucigalpa, Honduras. Fosdeh. Recuperado de: www. Fosdeh.com.

Falck, M. (2000). La finca humana. Homenaje a don Elías Sánchez, un forjador de la esperanza rural. Tegucigalpa, Honduras: RDS - HN. CIDICCO, Cosecha, Zamorano, 
Vecinos Mundiales, MOPAWl, PASOLAC: IC. Proyecto Lempira Sur, CARITAS, EPIC, EARTH, Paul Mckay.

Foucault, M. (1995). Qué es la crítica. Revista de Filosofía ULA, (11), pp. 5 - 25.

Freire, P. (1970). Pedagogía del oprimido. Buenos Aires, Argentina: Siglo XXI Editores.

García, V. (2000). La Economía Política y la Política Económica. México: Centro de Estudios Monetarios Latinoamericanos.

INE (2019). Censo de población y vivienda. Recuperado de http://170.238.108.227/binhnd/RpWebEngi ne.exe/Portal?BASE=MUNDEP14\&lang=ES $\mathrm{P}$

Jansen, K. (1993). Café y Formas de Producción en Honduras. Revista Centroamericana de Economía, 14 (41), pp. $58-96$.

Montes, Maldonado, C. (1928). El Cultivo Racional del Café en Honduras. Tegucigalpa, Honduras: Tipografía Nacional.

Orellana, J. (2018). Hacia otro paradigma de economía política del café y desarrollo humano en la región occidental de Honduras. (Tesis de doctorado). UNAH, Tegucigalpa, Honduras.
Orellana, J. y Carranza, A. (2013a). La Investigación Científica en la Historia y Cultura del Café en el Occidente de Honduras. La pequeña propiedad familiar. Paradigma, 20(32), pp. 135 - 152.

Orellana, J. y Carranza, A. (2013b). La Investigación Científica en la Historia y Cultura del Café en el Occidente de Honduras. La pequeña propiedad familiar. Paradigma, 20(32), pp. 135 - 152.

PNUD (2012). Informe sobre Desarrollo Humano, Honduras 2011. San José, Costa Rica: Litografía e Imprenta LIL, S.A.

PNUD (2009). Informe sobre Desarrollo Humano Honduras 2008/2009. San José, Costa Rica: Litografía e Imprenta LIL, S.A.

Rahnema, M. (1996). Pobreza, en W. SACHS (editor), Diccionario del desarrollo. Una guía del conocimiento como poder. Perú: PRATEC.

Santos, B. (2010a). Descolonizar el Saber, Reinventar el Poder. Montevideo, Uruguay: Ediciones Trilce.

Santos, B. (2010b). Para Descolonizar Occidente: Más Allá del Pensamiento Abismal, Buenos Aires, Argentina: CLACSO. 